\title{
REGULAÇÃO DA INVESTIGAÇÃO DE PATERNIDADE BIOLÓGICA: PERSPETIVA COMPARADA ${ }^{1}$
}

\author{
Helena Cristina Ferreira Machado, Susana Manuela Ribeiro Dias da Silva \\ e Diana Catarina de Oliveira Miranda \\ REGULATION OF BIOLOGICAL PATERNITY INVESTIGATION: \\ COMPARATIVE PERSPECTIVE
}

\section{RESUMO}

O OBJETIVO DESTE ARTIGO É ANALISAR COMPARATIVAMENTE A LEGISLAÇÃO RELATIVA À INVESTIGAÇ̃̃o DE PATERNIDADE BIOLÓGICA DE CRIANÇAS NASCIDAS FORA DO CASAMENTO NO BRASIL E EM PAÍSES EUROPEUS, COM BASE EM PESQUISA DE DOCUMENTOS LEGISLATIVOS PELA INTERNET E NA CONSULTA DE BIBLIOGRAFIA JURÍDICA NO ÂMBITO DO DIREITO DA FAMÍLIA. FOI ELABORADA UMA TIPOLOGIA LEGISLATIVA - VERDADE BIOLÓGICA ABSOLUTA E VERDADE BIOLÓGICA RELATIVA - ATENDENDO ÀS SEGUINTES VARIÁVEIS: FORMAS DE ATRIBUIÇÃO DA PATERNIDADE (VOLUNTÁRIA/ORDEM DO TRIBUNAL); TIPO DE CONSENTIMENTO EXIGIDO PARA REALIZAÇĀO DO TESTE GENÉTICO (VOLUNTÁRIO/FORÇADO); AUTOR DA INVESTIGAÇÃO (ESTADO/OUTROS); E LIMITE TEMPORAL DA INVESTIGAÇÃO (EXISTÊNCIA DE PRAZOS PROCESSUAIS/AUSÊNCIA DE PRAZO PROCESSUAL). A VERDADE BIOLÓGICA ABSOLUTA OCORRE QUANDO A INVESTIGAÇÃO DE PATERNIDADE DECORRE OBRIGATORIAMENTE, PODENDO SER ORDENADO E FORÇADO PELO TRIBUNAL O RECURSO AO TESTE genÉtico. OBSERVOU-SE A PREVAlênCIA DA VERDADE BIOLÓGICA RELATIVA. EM TODOS OS PAÍSES ANALISADOS VERIFICOUSE QUE O RECURSO AO TESTE GENÉTICO É PREPONDERANTE NO ESTABELECIMENTO DAS RELAÇõES DE FILIACCÃOO. MESMO EM PAÍSES EM QUE É NECESSÁRIO O CONSENTIMENTO PARA A REALIZACC̃̃O DE TESTE DE DNA EXISTEM MODALIDADES DE SUBMISSÃO MAIS SUBTIS, QUE INCLUEM A APLICAÇÃO DE MULTAS OU A GERAÇÃO DA PRESUNÇÃO DA PATERNIDADE COM BASE NA RECUSA EM REALIZAR EXAME GENÉTICO.

\section{PALAVRAS-CHAVE}

Paternidade; Verdade biológica; exame genético; CONSENTIMENTO INFORMADO.

\section{ABSTRACT}

THE AIM OF THIS ARTICLE IS TO DO A COMPARATIVE ANALYSIS RELATIVE TO THE INVESTIGATION OF BIOLOGICAL PATERNITY OF CHILDREN BORN OUT OF WEDLOCK IN BRAZIL AND EUROPEAN COUNTRIES, BASED ON THE RESEARCH OF LEGISLATIVE DOCUMENTS THROUGH THE INTERNET AND THE CONSULTATION OF LEGAL BIBLIOGRAPHY IN THE AREA OF FAMILY LAW. THE LEGISLATIVE TYPOLOGY WAS MADE - ABSOLUTE BIOLOGICAL TRUTH AND RELATIVE BIOLOGICAL TRUTH - ACCORDING TO THE FOLLOWING VARIABLES: FORMS OF PATERNAL ATTRIBUTION (VOLUNTARY/COURT ORDERED), TYPE OF DEMANDED CONSENT FOR THE PERFORMANCE OF THE GENETIC TEST

(VOLUNTARY/FORCED), AUTHOR OF THE INVESTIGATION (STATE/OTHER) AND THE TIME LIMIT OF THE INVESTIGATION (EXISTENCE OF PROCESS DEADLINES/NO PROCESS DEADLINES). THE ABSOLUTE BIOLOGICAL TRUTH OCCURS WHEN THE INVESTIGATION OF PATERNITY IS COMPULSORY AND THE COURT MIGHT ORDER AND FORCE THE SUBMISSION TO A GENETIC TEST. THE DOMINATING TREND IS RELATIVE BIOLOGICAL TRUTH. IN ALL ANALYSED COUNTRIES IT HAS BEEN VERIFIED THAT THE RESOURCE TO GENETIC TESTING IS PREPONDERANT WHEN ESTABLISHING AFFILIATION RELATIONS. EVEN IN COUNTRIES WHERE IT'S NOT POSSIBLE TO FORCE AN INDIVIDUAL TO THE SUBMISSION OF A GENETIC EXAM, THERE ARE MORE SUBTLE WAYS OF SUBMISSION, THAT INCLUDE THE APPLICATION OF FINES OR THE ASSUMPTION OF PATERNITY BASED ON A REFUSAL TO PERFORM THE GENETIC EXAM.

\section{KEYWORDS}

PATERNITY; BIOLOGICAL TRUTH; GENETIC TEST; INFORMED CONSENT. 


\section{INTRODUÇÃO}

As crianças nascidas fora do casamento institucional sempre foram um problema para os sistemas jurídicos ocidentais, que baseavam a transmissão de herança nos princípios da família patriarcal. A incerteza da paternidade fez com que se assistisse a uma forte convergência dos sistemas jurídicos ocidentais no que diz respeito à regulação legal das relações de filiação. Tais relações estão assentadas em duas dimensões essenciais existentes no direito romano, as quais se tornaram os pilares básicos da legislação produzida e aplicada nesse domínio específico: (i) o primado do casamento institucional como fonte das relações de filiação e a (ii) distinção entre filiação legítima e filiação ilegítima.

O primado do casamento institucional como fonte das relações de filiação revela-se de um modo particularmente claro na máxima latina pater is est quem nuptiae demonstrat - o pai é o marido da mãe -, que existia no antigo direito romano e que ainda subsiste na esmagadora maioria dos sistemas jurídicos europeus e também no Brasil, cujo direito de família foi, desde pelo menos o século XVII, fortemente condicionado pelas leis importadas do Império Português (Wehling e Wehling, 1999). Já o segundo fundamento das relações de filiação assentava no princípio de que o filho era legítimo se o pai era casado com a mãe; verificando-se a filiação ilegítima quando, no momento do nascimento do filho, o pai e a mãe não eram casados entre si. Essa separação binária e a consequente desigualdade de estatuto jurídico que rodeava a classificação dos filhos consoante as circunstâncias do seu nascimento vigoraram na Europa e no Brasil até meados da década de 1980.

Os avanços da genética registados com a criação da tecnologia de identificação de indivíduos por perfil de DNA, por um biólogo inglês da Universidade de Leicester - o professor Alec Jeffreys - que, em 1985, inventou o método das impressões genéticas, permitiu generalizar o uso do teste genético de paternidade nos tribunais ao longo da década de 1990 para efeito de determinação legal da paternidade. Atualmente, os exames genéticos comprovam a existência de laços biológicos entre indivíduos com uma margem de erro muito baixa, conseguindo confirmar a paternidade e a maternidade biológicas de determinado indivíduo com graus de certeza que podem atingir os 99,9\%. Por esse motivo, a verdade biológica estabelecida pelo exame de DNA assume um papel cada vez mais preponderante no estabelecimento legal da paternidade, como atesta o facto de a esmagadora maioria das jurisdições europeias, assim como no Brasil, consagrar o teste de DNA como uma prova determinante para o estabelecimento jurídico das relações de filiação (Eeekelaar e Sarcevic, 1993; European Commission, 1997).

Essa expansão do teste genético de paternidade surgiu, em vários países, associada à emergência do direito à identidade genética (que passaria pelo direito a saber quem são os progenitores biológicos). Em países como Portugal e Brasil esse direito à identidade genética pode ser financiado pelo Estado, em determinadas circunstâncias, e 
surgiu sob a égide do progresso e da consolidação da democracia (Fonseca, 2008; Machado, 2007). Para além do direito da criança à identidade pessoal por via do conhecimento das suas origens genéticas, a determinação legal de quem é o pai (biológico) de determinada criança é também geralmente justificada pelo direito à educação, à subsistência, a receber cuidados diários e supervisão de dois adultos de sexo diferente, à integridade psicológica e também à saúde, considerando-se, nesse último caso, a importância da identificação dos progenitores para a elaboração de um correto historial médico com base na historicidade genética (Erikson e Saldeen, 1993).

Os sistemas legais diferem quanto à regulação da investigação da paternidade biológica (European Commission, 1997; Forder e Saarloos, 2007), em particular nos seguintes aspectos: (i) a obrigatoriedade ou não de submissão ao exame genético; (ii) a necessidade ou não de consentimento por parte dos intervenientes e as possíveis consequências da recusa em realizar o exame; (iii) a autoria da investigação, isto é, quem deve desencadear a ação de investigação de paternidade, o Estado e/ou algum interessado (filho, mãe, pretenso pai); e (iv) o estabelecimento ou não de limites temporais para dar início a essa mesma ação.

Neste texto pretende-se analisar comparativamente os enquadramentos jurídicolegais do Brasil e de 17 países europeus sobre as modalidades de estabelecimento judicial da paternidade com base nesses quatro aspetos principais que os diferenciam.

\section{Metodologia}

A recolha de informação de diversas legislações relativamente ao estabelecimento da paternidade foi efetuada entre janeiro e maio de 2010. Com exceção do Brasil (Lei $\mathrm{n}^{\circ} 8.560$, de 29 de dezembro de 1992), os países não foram previamente selecionados para a realização do estudo, tendo sido apenas considerados aqueles cuja informação estava acessível após pesquisa exaustiva de bibliografia no âmbito do direito de família nos seguintes motores de pesquisa jurídica: Lexadin (lexadin.nl) e N-lex (eur-lex.europa.eu). Foram 18 os países alvo de estudo e análise, a saber: Alemanha, Áustria, Bélgica, Brasil, Dinamarca, Espanha, Finlândia, França, Grécia, Holanda, Inglaterra, Islândia, Itália, Noruega, Portugal, Rússia, Suécia e Suíça.

Realizamos uma análise comparativa com base em quatro critérios, que passamos a descrever:

1. Formas de atribuição da paternidade (voluntária/ordem do tribunal). Uma das formas de atribuir a paternidade é pelo reconhecimento voluntário da mesma, apesar de este por vezes depender do consentimento da mãe e/ou do filho, e até da aprovação do juiz. Esse reconhecimento pode ser feito pela perfilhação: o indivíduo identifica-se livremente como pai para efeito de preenchimento da identidade dos progenitores no registo de nascimento. A atribuição da paternidade também pode 
ser feita de forma involuntária, estando sujeita a uma decisão judicial. Nesse caso, o estabelecimento da paternidade deriva de um processo judicial desencadeado para investigar a paternidade, uma vez que no registo de nascimento da criança não consta o nome do pai. Para esse efeito, pode haver recurso - por parte dos intervenientes no processo (mãe e pretenso pai da criança) ou de testemunhas - a declarações, bem como a realização de exames genéticos.

2. Tipo de consentimento exigido para realização do teste genético (voluntário/forçado). O exame genético ordenado pelo tribunal para efeitos de estabelecimento da paternidade pode ser realizado com ou sem consentimento dos intervenientes. Em caso de recusa de submissão ao exame genético, este poderá ser forçado, dando eventualmente lugar a consequências que vão desde a emissão de multas até período de prisão, ou mesmo inversão do ónus da prova.

3. Autoria da investigação de paternidade (Estado/outros). A ação judicial de investigação de paternidade pode ser intentada pelo próprio Estado, pela mãe, pelo pretenso pai ou pelo filho (menor ou maior de idade).

4. Limites temporais para estabelecer uma ação de investigação de paternidade (existência de prazos processuais/ausência de prazo processual). Quando existem prazos processuais para estabelecer a paternidade, estes decorrem normalmente após o nascimento do filho ou após a maioridade deste.

Essa análise permitiu identificar dois tipos principais de enquadramento legal, que classificamos como representativos de uma verdade biológica absoluta ou de uma verdade biológica relativa. Os principais vetores de diferenciação são o tipo de consentimento exigido para a realização do exame genético e a autoria da ação de investigação, de acordo com os critérios que descrevemos de seguida.

A primazia da verdade biológica absoluta verifica-se em países onde a investigação de paternidade decorre obrigatoriamente sempre que não esteja identificada a paternidade no registo de nascimento da criança e nos quais pode ser ordenado e forçado pelo tribunal o recurso à prova biológica. Nesses países, o estabelecimento da paternidade ganha contornos de obrigatoriedade e geralmente o Estado desencadeia a ação de investigação de paternidade, necessitando, para esse efeito, das declarações da mãe quanto à identificação do pai da criança. Nessas jurisdições, o recurso à prova biológica pode então ser ordenado pelo tribunal, e a realização do exame genético pode até ser forçada, desde que sustentada por uma ordem judicial (Boele-Woelki, 2003; Frank, 1996; Krause, 2007).

A primazia da verdade biológica relativa verifica-se em países onde normalmente a investigação de paternidade não é compulsória, ou seja, na maior parte desses casos 
a investigação de paternidade não é desencadeada pelo Estado, mas sim por iniciativa da mãe, do pretenso pai ou do filho e do respectivo representante legal (Krause, 2007). Apesar dos testes genéticos poderem ser ordenados pelo tribunal, não será possível forçar a realização do teste nos casos em que não há consentimento por parte dos intervenientes. Ainda assim, poderá haver meios de impelir os indivíduos a realizar o teste, dos quais são exemplo as consequências associadas às recusas, como multas e penas de prisão (European Commission, 1997; Frank, 1996).

\section{Resultados}

Dos 18 países em análise, 5 dão primazia à verdade biológica absoluta nas investigações de paternidade (Alemanha, Dinamarca, Islândia, Noruega e Suécia). A dominância da verdade biológica relativa assume-se como a tendência maioritária, ocorrendo em 13 dos 18 países analisados (Áustria, Bélgica, Brasil, Espanha, Finlândia, França, Grécia, Holanda, Inglaterra, Itália, Portugal, Rússia e Suíça).

Além do estabelecimento judicial de paternidade, a relação entre o pai e o filho também pode ser estabelecida por meio de um ato de reconhecimento voluntário por parte do pretenso pai em todas as legislações, onde este se identifica como pai para efeito de preenchimento do registo de nascimento (tabela 1). Em alguns países favorece-se o procedimento voluntário e há uma restrição dos procedimentos obrigatórios (caso de França), sendo que é presumido que o pai é aquele homem que reconhece o filho e não é necessário o consentimento da mãe. Em muitos outros casos é necessário haver consentimento e aprovação do filho e/ou da mãe (Alemanha, Brasil, Dinamarca, Finlândia, Grécia, Holanda, Inglaterra, Rússia, Suécia) e até do juiz (Espanha) (Frank, 2005; Krause, 2007).

O estabelecimento da paternidade é, assim, tido como obrigatório nos países onde é valorizada a verdade biológica absoluta, sendo que geralmente é o Estado que desencadeia a ação de investigação de paternidade. Nesses países a mãe tem o dever de referir quem é o pai da criança, sob pena de não receber apoio social para o filho (casos da Noruega e da Suécia) ou de receber uma multa (Alemanha). Nos países onde é valorizada a verdade biológica relativa normalmente a mãe não tem o dever de revelar a identidade do pai; contudo, em Inglaterra, se a mãe se recusar a indicar a identidade do pai poderá ser retirado do filho o apoio social (McGlynn, 2006).

Relativamente à realização do exame genético importa analisar o tipo de consentimento exigido e as consequências da recusa de submissão ao teste de paternidade (tabela 2). Assim, nos países onde predomina a verdade biológica absoluta é obrigatório o recurso ao exame genético e este é efetuado independentemente de haver ou não consentimento por parte dos intervenientes, sendo forçado com ordem judicial (excetuando o caso da Alemanha, onde não é permitida a realização do exame sem consentimento, apesar de poder haver coação) (Boele-Woelki, 2003; Eeekelaar e 
Sarcevic, 1993). No conjunto de países enquadráveis na verdade biológica relativa é necessário o consentimento dos intervenientes, mesmo que os exames possam ser ordenados pelo tribunal. Contudo, em caso de recusa de submissão ao exame podem surgir consequências que vão desde emissão de multas e/ ou período de prisão (Áustria, Grécia e Suíça) até inversão do ónus da prova (Inglaterra e Portugal), isto é, passa o pai a ter o ónus de provar a inexistência de relação de parentesco, ou seja, provar que não é ele o pai (European Commission, 1997; Frank, 1993, 1996).

No que respeita ao autor da investigação de paternidade constata-se que, excetuando a Islândia, em todos os países onde é valorizada a verdade biológica absoluta o Estado tem o dever de iniciar a investigação de paternidade (tabela 3). Na Finlândia, na Inglaterra e em Portugal também cabe ao Estado a iniciativa de desencadear a investigação de paternidade, mesmo sendo países que valorizam a verdade biológica relativa.

Além do Estado, também o filho, a mãe e o pretenso pai podem iniciar uma investigação de paternidade. No caso da Alemanha, da Finlândia e da Inglaterra todos o podem fazer. Noutros países apenas o pretenso pai (Dinamarca e Suécia) ou o Estado (Islândia) não podem desencadear a investigação de paternidade. Na grande maioria dos países (todos eles com predominância da verdade biológica relativa) somente o filho ou a mãe podem ser demandantes da investigação de paternidade, sendo que a mãe tende a ser a representante do filho quando este é menor (Áustria, Bélgica, França, Holanda, Itália, Suíça) (Krause, 2007). No caso português apenas o Estado e o filho podem desencadear a investigação de paternidade.

No que toca ao período-limite de admissibilidade da ação de investigação de paternidade, não há diferenças assinaláveis entre os países que valorizam a verdade biológica absoluta e os que valorizam a verdade biológica relativa (tabela 4). Em geral, consolida-se a tendência para eliminar a delimitação de prazos processuais.

\section{CONCLUSÃo}

A análise comparativa das diversas legislações sobre o estabelecimento da paternidade nos países em análise (Alemanha, Áustria, Bélgica, Brasil, Dinamarca, Espanha, Finlândia, França, Grécia, Holanda, Inglaterra, Islândia, Itália, Noruega, Portugal, Rússia, Suécia e Suíça) confirma a importância jurídica, social e simbólica da verdade biológica no estabelecimento das relações de filiação.

De acordo com as circunstâncias legais que enquadram a realização do exame genético para investigação da paternidade, e sobretudo no que diz respeito ao tipo de consentimento exigido para realização do exame e autoria do processo judicial de investigação de paternidade, podemos dividir os enquadramentos legislativos em dois grandes grupos: os que se associam à prevalência do que designamos como verdade biológica absoluta e os que se associam à prevalência da verdade biológica relativa. 
O recurso à prova biológica nas investigações de paternidade parece assumir-se como obrigatório e/ou ordenado pelo tribunal, sendo que nos países onde prevalece a concepção de verdade biológica absoluta a realização do exame genético pode até ser forçada com ordem judicial. Nos países onde prevalece a concepção de verdade biológica relativa a realização do exame genético não pode ser imposta, mas a recusa de submissão pode gerar a presunção de paternidade.

Pode concluir-se que nos países em análise a determinação da verdade biológica por intermédio de realização de exame genético é preponderante no estabelecimento das relações de filiação, à qual corresponde uma tentativa de fazer coincidir a paternidade biológica com a legal. Se o acesso a determinadas informações biogenéticas dos ascendentes é benéfico para a elaboração de um correto historial médico com base na historicidade genética, o mesmo não se pode concluir quanto aos impactos positivos da identificação legal da paternidade biológica no que concerne ao bem-estar das crianças. Torna-se, por isso, necessário associar à regulação jurídico-legal da paternidade a emancipação de todos os cidadãos envolvidos em investigações de paternidade biológica. Isso pode ser feito por meio, por exemplo, da identificação, da monitorização e do controlo dos impactos do estabelecimento legal da paternidade biológica no que tange a desigualdades de gênero no campo familiar e a respetivos direitos e responsabilidades de homens e mulheres (Teixeira, 2010).

As implicações dos usos dos testes genéticos na reconfiguração dos direitos das mães e dos pretensos pais também têm sido equacionadas em torno do direito a privacidade, integridade física e moral e autodeterminação informacional. Mas o debate deverá incorporar a questão do consentimento informado. A existência de diversos enquadramentos jurídico-legais com práticas de consentimento informado diversificadas pode dificultar a compreensão dos objetivos dos testes de DNA e a estandardização da comunicação dos seus resultados e dos seus efeitos nas relações de filiação. A obtenção de um consentimento informado deverá ser perspetivada como um direito dos cidadãos, cujo âmago é a prestação de informações perceptíveis sobre os objetivos, os procedimentos, os resultados e as implicações dos testes genéticos, o que se afigura como um desafio para a regulação transnacional das boas práticas jurídicas e científicas na investigação de paternidade biológica.

: ARTIGO APROVADO (02/12/2012) : RECEBIDO EM 25/02/2011 


\section{NOTAS}

1 Este trabalho resulta do projecto "Mães e pais depois da "verdade biológica"? Género, desigualdades e papéis parentais”, FCOMP-01-0124-FEDER-008483, coordenado pela primeira autora, financiado pela Fundação para a Ciência e a Tecnologia (Ministério da Ciência, Tecnologia e Ensino Superior, Portugal) e apoiado pela Comissão para a Igualdade de Género.

\section{REFERÊNCIAS BIBLIOGRÁFICAS}

BOELE-WOELKI, K. Perspectives for the unification and harmonisation of family law in Europe. [S.1.]: Intersentia, 2003. EEKELAAR, J.; SARCEVIC, P. Parenthood in modern society: legal and social issues for the twenty-first century. Dordrecht: Martinus Nijhoff, 1993.

ERIKSON, A ; SALDEEN, A. Parenthood and science: establishing and contesting parentage. In: EEKELAAR, J.; SARCEVIC, P. (Ed.). Parenthood in modern society: legal and social issues for the twenty-first century. Dordrecht: Martinus Nijhoff, 1993. p. 75-92.

EUROPEAN COMMISSION. Studies on the socio-economic impact of biotechnology: genetic fingerprints, scientific truth and affiliation law. Luxembourg: Official Publications of the European Communities, 1997.

FONSECA, C. "Ordem e progresso" à brasileira: lei, ciência e gente na "co-produção" de novas moralidades familiares. In: REUNIÃO DE ANTROPOLOGIA BRASILEIRA, 26., 2008, Porto Seguro. Anais... Porto Seguro, 1-4 jun. 2008.

FORDER, C.; SAARLOOS, K. The establishment of parenthood: a story of successful convergence. In: ANTOKOLSKAIA, M. (Ed.). Convergence and divergence of family law in Europe. Oxford: Intersentia, 2007. p. $169-236$.

FRANK, R. La signification différente attachée a la filiation par le sang en droit allemand et français de la famille. Revue Internationale de Droit Comparé, Paris, n. 3, p. 635-655, 1993.

Compulsory physical examinations for establishing parentage. International Journal of Law, Policy and the Family, Oxford University Press, v. 10, n. 2, p. 205-218, 1996.

. Le droit de connaître ses origines : comparaison franco-allemande. In: VOGEL, L. (Ed.). Des droits au droit : les droits de la personne, fondement du droit. [S.1.]: L. G. D. J. Diffuseur, 2005. p. 10-23.

KRAUSE, H. Creation of relationships of kinship. In: CHLOROS, A. (Ed.). International encyclopedia of comparative law. Haia: Martinus Nijhoff, 2007. v. 4. p. 28-56.

MACHADO, H. Moralizar para identificar: cenários da investigação social da paternidade. Porto: Afrontamento, 2007. MCGLYNN, C. Families and the European Union: law, politics and pluralism. Cambridge: CUP, 2006.

TEIXEIRA, D. V. Desigualdade de gênero: sobre garantias e responsabilidades sociais de homens e mulheres. Revista Direito GV, São Paulo, v. 6, n. 1, p. 253-274, jan./jun. 2010.

WEHLING, A.; WEHLING, M. O direito de família no mundo luso-brasileiro: período pombalino e póspombalino. Revista do Instituto Histórico Geográfico Brasileiro, Rio de Janeiro, v. 404, p. 537-546, 1997. 


\section{Tabela 1. AnÁlise COMPARATIVA dA LEGISLAÇÃo QUANTO ÀS DiFERENTES FORMAS DE RECONHECIMENTO DA PATERNIDADE}

\begin{tabular}{|c|c|c|c|}
\hline PAÍS & $\begin{array}{l}\text { RECONHECIMENTO } \\
\text { VOLUNTÁRIO }\end{array}$ & $\begin{array}{l}\text { INVESTIGAÇÃO } \\
\text { COMPULSÓRIA }\end{array}$ & NOTAS \\
\hline \multicolumn{4}{|c|}{ VERDADE BIOLÓGICA ABSOLUTA } \\
\hline ALEMANHA & $\sqrt{ }$ & $\sqrt{ }$ & $\begin{array}{l}\text { O CONSENTIMENTO DO FILHO (QUE } \\
\text { PODE SER REPRESENTADO PELA MÃE) É } \\
\text { NECESSÁRIO PARA O RECONHECIMENTO. } \\
\text { O TRIBUNAL É OBRIGADO A RECOLHER } \\
\text { TODAS AS PROVAS NECESSÁRIAS, E AS } \\
\text { PESSOAS ENVOLVIDAS SÃO OBRIGADAS } \\
\text { A COOPERAR. A MÃE NÃO TEM O DEVER } \\
\text { DE INFORMAR QUEM É O PAI, MAS } \\
\text { PODE TER QUE PAGAR UMA MULTA SE } \\
\text { O RECUSAR. }\end{array}$ \\
\hline DINAMARCA & $\sqrt{ }$ & $\sqrt{ }$ & $\begin{array}{l}\text { O CONSENTIMENTO DA MÃE É } \\
\text { NECESSÁRIO PARA O RECONHECIMENTO. } \\
\text { A MÃE TEM O DEVER DE INFORMAR } \\
\text { QUEM É O PAI. }\end{array}$ \\
\hline ISLÂNDIA & $\sqrt{ }$ & $\sqrt{ }$ & $\begin{array}{l}\text { A MÃE TEM O DEVER DE INFORMAR } \\
\text { QUEM É O PAI. }\end{array}$ \\
\hline NORUEGA & $\sqrt{ }$ & $\sqrt{ }$ & $\begin{array}{l}\text { A MÃE TEM QUE DIZER QUEM É O PAI } \\
\text { PARA A CRIANÇA RECEBER APOIO. }\end{array}$ \\
\hline SUÉCIA & $\sqrt{ }$ & $\sqrt{ }$ & $\begin{array}{l}\text { O CONSENTIMENTO DA MÃE É } \\
\text { NECESSÁRIO PARA O RECONHECIMENTO. } \\
\text { A MÃE TEM QUE DIZER QUEM É O PAI } \\
\text { PARA A CRIANÇA RECEBER APOIO. }\end{array}$ \\
\hline
\end{tabular}

VERDADE BIOLÓGICA RELATIVA

\begin{tabular}{llll}
\hline ÁUSTRIA & $\sqrt{ }$ & $\times$ & \\
\hline BÉLGICA & $\sqrt{ }$ & $\begin{array}{l}\text { É ADMISSÍVEL UM EXAME REALIZADO } \\
\text { SEM ORDEM JUDICIAL E EFETUADO NO } \\
\text { SETOR PRIVADO. }\end{array}$ \\
\hline BRASIL & & O CONSENTIMENTO DO FILHO ISE ESTE \\
& $\sqrt{ }$ & FOR MAIOR DE IDADE) É NECESSÁRIO \\
& & PARA O RECONHECIMENTO. A INICIATIVA \\
& CONFERIDA AO ESTADO NÃO IMPEDE \\
& QUE QUEM TENHA LEGITIMO INTERESSE \\
& INTENTE A INVESTIGAÇÃO. \\
\hline
\end{tabular}

\begin{tabular}{lll}
\hline ESPANHA & $\times$ & PARA O RECONHECIMENTO, É
\end{tabular}
NECESSÁRIO OU O CONSENTIMENTO DA MÃE IOU DO REPRESENTANTE DO MENOR), OU A APROVAÇÃO DO JUIZ (EM CASO DE MENORIDADE DO FILHO) OU O CONSENTIMENTO DO PRÓPRIO FILHO (EM CASO DE MAIORIDADE). 


\begin{tabular}{|c|c|c|c|}
\hline FRANÇA & $\sqrt{ }$ & $x$ & $\begin{array}{l}\text { PRESUME-SE QUE QUEM RECONHECE } \\
\text { A PATERNIDADE É DE FATO O PAI, } \\
\text { NÃO HAVENDO NECESSIDADE DE } \\
\text { CONSENTIMENTO DA MÃE. }\end{array}$ \\
\hline GRÉCIA & $\sqrt{ }$ & $x$ & $\begin{array}{l}\text { O CONSENTIMENTO DA MÃE É } \\
\text { NECESSÁRIO PARA O RECONHECIMENTO. }\end{array}$ \\
\hline HOLANDA & $\sqrt{ }$ & $x$ & $\begin{array}{l}\text { O CONSENTIMENTO DA MÃE (NO CASO } \\
\text { DE O FILHO TER MENOS DE } 16 \text { ANOS) } \\
\text { OU DO DO FILHO (SE ESTE TIVER MAIS } \\
\text { DE } 12 \text { ANOS) É NECESSÁRIO PARA O } \\
\text { RECONHECIMENTO. A MÃE NÃO TEM } \\
\text { O DEVER DE INFORMAR QUEM É O PAI. }\end{array}$ \\
\hline INGLATERRA & $\sqrt{ }$ & $x$ & $\begin{array}{l}\text { O CONSENTIMENTO DA MÃE É } \\
\text { NECESSÁRIO PARA O } \\
\text { RECONHECIMENTO. A MÃE NÃO TEM } \\
\text { QUE REVELAR A IDENTIDADE DO PAI, } \\
\text { MAS, SE NÃO O FIZER, PERDE O APOIO } \\
\text { DA SEGURANÇA SOCIAL. }\end{array}$ \\
\hline ITÁLIA & $\sqrt{ }$ & $x$ & \\
\hline PORTUGAL & $\sqrt{ }$ & $\sqrt{ }$ & \\
\hline RÚSSIA & $\sqrt{ }$ & $x$ & $\begin{array}{l}\text { O CONSENTIMENTO DA MÃE É } \\
\text { NECESSÁRIO PARA O RECONHECIMENTO. }\end{array}$ \\
\hline suÍçA & $\sqrt{ }$ & $x$ & $\begin{array}{l}\text { É ADMISSÍVEL UM EXAME ORDENADO } \\
\text { SEM ORDEM JUDICIAL E REALIZADO } \\
\text { NO SETOR PRIVADO. }\end{array}$ \\
\hline
\end{tabular}

Tabela 2. AnÁlise COMPARATIVA dA LEGislaÇÃo QUANTO AO TIPO DE CONSENTIMENTO INFORMADO EXIGIDO E ÀS CONSEQUÊNCIAS DA RECUSA EM REALIZAR O EXAME GENÉTICO

\begin{tabular}{lll} 
PAÍS & CONSENTIMENTO INFORMADO & RECUSA EM REALIZAR O EXAME GENÉTICO \\
\hline VERDADE BIOLÓGICA ABSOLUTA & \\
\hline ALEMANHA & OBRIGATÓRIO. & $\begin{array}{l}\text { A RECUSA SEM JUSTIFICAÇÃO PODE SER } \\
\text { SANCIONADA COM PERIOODO DE PRISÃO, E A } \\
\text { PESSOA PODE SER FORÇADA A REALIZAR O EXAME. }\end{array}$ \\
\hline DINAMARCA & NÃO OBRIGATÓRIO. & O EXAME PODE SER FORÇADO COM ORDEM JUDICIAL. \\
\hline ISLÂNDIA & NÃO OBRIGATÓRIO. & O EXAME PODE SER FORÇADO COM ORDEM JUDICIAL. \\
\hline NORUEGA & NÃO OBRIGATÓRIO. & O EXAME PODE SER FORÇADO COM ORDEM JUDICIAL. \\
\hline SUÉCIA & NÃO OBRIGATÓRIO. & O EXAME PODE SER FORÇADO COM ORDEM JUDICIAL \\
& E, EM ÚLTIMO CASO, PELA POLÍCIA (COM EXCEÇÃO \\
\hline VERDADE BIOLÓGICA RELATIVA & DE CRIANCCAS MENORES DE 18 ANOS). \\
\hline ÁUSTRIA & \\
\hline & OBRIGATÓRIO. & PODE HAVER EMISSÃO DE MULTAS OU \\
& ESTABELECIMENTO DE PERÍODO DE PRISÃO EM
\end{tabular}




\begin{tabular}{|c|c|c|}
\hline BRASIL & OBRIGATÓRIO. & $\begin{array}{l}\text { A RECUSA DO PRETENSO PAI EM SUBMETER-SE } \\
\text { AO EXAME GERARÁ A PRESUNÇÃO DE, } \\
\text { PATERNIDADE A SER APRECIADA EM CONJUNTO } \\
\text { COM O CONTEXTO PROBATÓRIO. }\end{array}$ \\
\hline ESPANHA & OBRIGATÓRIO. & SEM INFORMAC̣ÃO. \\
\hline FINLÂNDIA & OBRIGATÓRIO. & SEM INFORMAÇÃO. \\
\hline FRANÇA & OBRIGATÓRIO. & $\begin{array}{l}\text { CABE AO JUIZ INTERPRETAR OS SIGNIFICADOS } \\
\text { DA RECUSA. }\end{array}$ \\
\hline GRÉCIA & OBRIGATÓRIO. & PODEM SER EMITIDAS MULTAS EM CASO DE RECUSA. \\
\hline HOLANDA & OBRIGATÓRIO. & $\begin{array}{l}\text { CABE AO JUIZ INTERPRETAR OS SIGNIFICADOS } \\
\text { DA RECUSA. }\end{array}$ \\
\hline INGLATERRA & OBRIGATÓRIO. & $\begin{array}{l}\text { OS EXAMES NÃO PODEM SER FORÇADOS NOS } \\
\text { CIDADÃOS MAIORES DE } 16 \text { ANOS, MAS PODEM } \\
\text { SÊ-LO NO CASO DAS CRIANÇAS. A RECUSA SERVIRÁ } \\
\text { PARA INVERTER O ÓNUS DA PROVA. }\end{array}$ \\
\hline ITÁLIA & OBRIGATÓRIO. & $\begin{array}{l}\text { CABE AO JUIZ INTERPRETAR OS SIGNIFICADOS } \\
\text { DA RECUSA. }\end{array}$ \\
\hline PORTUGAL & OBRIGATÓRIO. & $\begin{array}{l}\text { A RECUSA SERVIRÁ PARA INVERTER O ÓNUS } \\
\text { DA PROVA. }\end{array}$ \\
\hline RÚSSIA & OBRIGATÓRIO. & SEM INFORMAC̦ÃO. \\
\hline SuÍçA & OBRIGATÓRIO. & $\begin{array}{l}\text { PODE HAVER EMISSÃO DE MULTAS OU } \\
\text { ESTABELECIMENTO DE PERÍODO DE PRISÃO } \\
\text { EM CASO DE RECUSA. }\end{array}$ \\
\hline
\end{tabular}

\section{Tabela 3. AnÁlise COMPARATIVA dA LEGISLAÇÃo QUANTO AO AUTOR DA INVESTIGAÇÃO DE PATERNIDADE}

\begin{tabular}{|c|c|c|c|c|c|}
\hline PAÍS & ESTADO & FILHO/A & MÃE & PRETENSO PAI & NOTAS \\
\hline \multicolumn{6}{|c|}{ VERDADE BIOLÓGICA ABSOLUTA } \\
\hline ALEMANHA & $\sqrt{ }$ & $\sqrt{ }$ & $\sqrt{ }$ & $\sqrt{ }$ & \\
\hline DINAMARCA & $\sqrt{ }$ & $\sqrt{ }$ & $\sqrt{ }$ & $x$ & \\
\hline ISLÂNDIA & $\times$ & $\sqrt{ }$ & $\sqrt{ }$ & $\sqrt{ }$ & \\
\hline NORUEGA & $\sqrt{ }$ & $?$ & $?$ & $x$ & \\
\hline SUÉCIA & $\sqrt{ }$ & $\sqrt{ }$ & $\sqrt{ }$ & $x$ & $\begin{array}{l}\text { O MENOR TEM UM REPRESENTANTE, } \\
\text { QUE PODE SER A MÃE. }\end{array}$ \\
\hline \multicolumn{6}{|c|}{ VERDADE BIOLÓGICA RELATIVA } \\
\hline ÁUSTRIA & $x$ & $\sqrt{ }$ & $\sqrt{ }$ & $x$ & $\begin{array}{l}\text { O MENOR TEM UM REPRESENTANTE, } \\
\text { QUE PODE SER A MÃE. }\end{array}$ \\
\hline BÉLGICA & $x$ & $\sqrt{ }$ & $\sqrt{ }$ & $x$ & $\begin{array}{l}\text { O MENOR TEM UM REPRESENTANTE, } \\
\text { QUE PODE SER A MÃE. }\end{array}$ \\
\hline BRASIL & $\sqrt{ }$ & $\sqrt{ }$ & $\sqrt{ }$ & $\sqrt{ }$ & $\begin{array}{l}\text { O MENOR TEM UM REPRESENTANTE, } \\
\text { QUE PODE SER A MÃE. }\end{array}$ \\
\hline
\end{tabular}


584 : REgULAÇÃo dA INVESTIGAÇÃo dE PATERNIDAdE BIOLÓGICA: PERSPETIVA COMPARADA

\begin{tabular}{|c|c|c|c|c|c|}
\hline ESPANHA & ? & ? & ? & ? & \\
\hline FINLÂNDIA & $\sqrt{ }$ & $\sqrt{ }$ & $\sqrt{ }$ & $\sqrt{ }$ & $\begin{array}{l}\text { PRETENSO PAI SÓ É AUTOR QUANDO } \\
\text { NÃO ACEITA O RECONHECIMENTO } \\
\text { DE PATERNIDADE. }\end{array}$ \\
\hline FRANCCA & $x$ & $\sqrt{ }$ & $\sqrt{ }$ & $x$ & $\begin{array}{l}\text { MÃE SÓ É AUTORA DURANTE A } \\
\text { MENORIDADE DA CRIANÇA. }\end{array}$ \\
\hline GRÉCIA & $?$ & $?$ & $?$ & $?$ & \\
\hline HOLANDA & $x$ & $\sqrt{ }$ & $\sqrt{ }$ & $x$ & $\begin{array}{l}\text { O MENOR TEM UM REPRESENTANTE, } \\
\text { QUE PODE SER A MÃE, ATÉ TER } 16 \text { ANOS. }\end{array}$ \\
\hline INGLATERRA & $\sqrt{ }$ & $\sqrt{ }$ & $\sqrt{ }$ & $\sqrt{ }$ & \\
\hline ITÁLIA & $x$ & $\sqrt{ }$ & $\sqrt{ }$ & $x$ & \\
\hline PORTUGAL & $\sqrt{ }$ & $\sqrt{ }$ & $x$ & $x$ & \\
\hline RÚSSIA & $?$ & $?$ & $?$ & $?$ & \\
\hline SuÍçA & $x$ & $\sqrt{ }$ & $\sqrt{ }$ & $x$ & \\
\hline
\end{tabular}

Tabela 4. ANÁlise COMPARATIVA dA LEGISLAÇÃo QUANTO AO PERÍODOLIMITE DE ADMISSIBILIDADE DA AÇÃO DE INVESTIGAÇÃO DE PATERNIDADE

\begin{tabular}{|c|c|c|c|}
\hline PAÍS & $\begin{array}{l}\text { APÓS O NASCIMENTO } \\
\text { DO FILHO }\end{array}$ & $\begin{array}{l}\text { APÓS O FILHO ATINGIR } \\
\text { A MAIORIDADE }\end{array}$ & NOTAS \\
\hline \multicolumn{4}{|c|}{ VERDADE BIOLÓGICA ABSOLUTA } \\
\hline ALEMANHA & TEMPO INDETERMINADO. & TEMPO INDETERMINADO. & \\
\hline DINAMARCA & 3 ANOS. & SEM INFORMAÇÃO. & \\
\hline ISLÂNDIA & SEM INFORMAÇÃO. & SEM INFORMAÇÃO. & \\
\hline NORUEGA & SEM INFORMAÇÃO. & SEM INFORMAÇÃO. & \\
\hline SUÉCIA & $\begin{array}{l}\text { DURANTE A } \\
\text { MENORIDADE. }{ }^{1}\end{array}$ & $\begin{array}{l}\text { TEMPO } \\
\text { INDETERMINADO. } 2\end{array}$ & $\begin{array}{l}1 \text { SE A AÇÃO FOR DESENCADEADA PELO } \\
\text { REPRESENTANTE DO MENOR OU PELA MÃE. } \\
2 \text { NO CASO DE A AÇÃO SER INICIADA } \\
\text { PELO FILHO. }\end{array}$ \\
\hline
\end{tabular}

\begin{tabular}{|c|c|c|c|}
\hline \multicolumn{4}{|c|}{ VERDADE BIOLÓGICA RELATIVA } \\
\hline ÁUSTRIA & SEM INFORMAÇÃO. & SEM INFORMAÇÃO. & \\
\hline BÉLGICA & SEM INFORMAÇÃO. & SEM INFORMAC̣ÃO. & \\
\hline BRASIL & DURANTE A MENORIDADE. & 2 ANOS. & \\
\hline ESPANHA & TEMPO INDETERMINADO. & TEMPO INDETERMINADO. & \\
\hline FINLÂNDIA & 2 ANOS. & SEM INFORMAC̣ÃO. & $\begin{array}{l}\text { UM ANO APENAS PARA O PRETENSO, } \\
\text { PAI APÓS ESTE TER SIDO INFORMADO } \\
\text { DA RECUSA DO SEU RECONHECIMENTO } \\
\text { DE PATERNIDADE. }\end{array}$ \\
\hline FRANÇA & 2 ANOS. & 10 ANOS. & $\begin{array}{l}\text { EM CASO DE COABITAÇÃO, A CONTAGEM } \\
\text { DOS } 2 \text { ANOS SÓ COMEÇA QUANDO A } \\
\text { RELAÇÃO ACABA. }\end{array}$ \\
\hline
\end{tabular}




\begin{tabular}{|c|c|c|c|}
\hline GRÉCIA & 5 ANOS. & 1 ANO. & \\
\hline HOLANDA & 5 ANOS. & ILIMITADO. & $\begin{array}{l}\text { A CONTAGEM DOS } 5 \text { ANOS COMEÇA COM } \\
\text { O NASCIMENTO DA CRIANÇA OU DEPOIS } \\
\text { DE SER CONHECIDA A LOCALIZAÇÃO DO } \\
\text { PRETENSO PAI. O TEMPO ILIMITADO SÓ } \\
\text { ACONTECE NO CASO DE A AÇÃO SER } \\
\text { INICIADA PELO FILHO. }\end{array}$ \\
\hline INGLATERRA & TEMPO INDETERMINADO. & TEMPO INDETERMINADO. & \\
\hline ITÁLIA & TEMPO INDETERMINADO. & TEMPO INDETERMINADO. & \\
\hline PORTUGAL & 2 ANOS. & 10 ANOS. & \\
\hline RÚSSIA & SEM INFORMAC̣ÃO. & SEM INFORMAÇÃO. & \\
\hline SUÍC̣A & 1 ANO. & 1 ANO. & \\
\hline
\end{tabular}

FONTES DA TABELAS 1, 2, 3 E 4: LEI N. 8.560 DE 29 DE DEZEMBRO DE 1992, PARA O CASO DO BRASIL. LEXADIN (LEXADIN.NL) E N-LEX (EURLEX.EUROPA.EU), PARA OS PAÍSES RESTANTES

\author{
Instituto de Ciências Sociais \\ Departamento de Sociologia \\ Campus de Gualtar - 4710-057 \\ Braga - Portugal \\ hmachadolics.uminho.pt
}

Instituto de Saúde Pública da Universidade do Porto Rua das Taipas, n. 135 4050-600 Porto - Portugal susilvalamed.up.pt

\section{Helena Cristina Ferreira Machado}

Professora Associada com Agregação do Departamento dE Sociologia da Universidade do Minho

INVESTIGADORA DO CENTRO DE INVESTIGAC̣ÃO EM CIÊNCIAS SoCIAIS NA UnIVERSIDADE do MINHO InVESTIGADORA AsSOCIADA DO CENTRO DE ESTUdOS SOCIAIS NA UNIVERSIDADE DE COIMBRA

\section{Susana Manuela Ribeiro Dias da Silva}

INVESTIGADORA AUXILIAR NO DEPARTAMENTO DE EPIDEMIOLOGIA Clínica, Medicina Preditiva e Saúde Pública da Faculdade de Medicina da Universidade do Porto

\section{Diana Catarina de Oliveira Miranda}

Instituto de Ciências Sociais Departamento de Sociologia Campus de Gualtar - 4710-057

Braga - Portugal mc10010囚direito.up.pt
LiCENCIADA EM SoCIOLOGIA PELA UnIVERSIDADE DO MINHO, COM ESPECIALIZAÇÃO EM CRIMINOLOGIA NA FACULdAdE DE DiREITO dA Universidade dO PORTO 
